\title{
Flow Field Simulation and Performance Analysis of HVAC Defrosting Duct
}

\author{
Wei Yang ${ }^{1, a}$, Wenku Shi ${ }^{1, b}$, Fuxiang Guo², Weilong Yang ${ }^{2}$ \\ ${ }^{1}$ State Key Laboratory of Automobile Dynamic Simulation, Jilin University, Changchun 130025 , \\ China \\ ${ }^{2}$ Nanjing Iveco Automotive Co. Ltd, Nanjing 2010028, China \\ a356661132@163.com; bshiwk@jlu.edu.cn
}

Keywords: defrosting duct; CFD; jet velocity

\begin{abstract}
Model of HVAC defrosting duct of a light bus was built, and inner air flow field features was simulated in CFD software FLUENT, from which we could acquire the outlet flow distribution and jet velocity. In addition, to find out whether the jet angle was reasonable, model of air flow area close to windshield was imported into FLUENT. Distribution of airflow velocity on the surface of windshield could reflect defrosting performance to some extent.
\end{abstract}

\section{Introduction}

Windshield defrosting performance is not only one of the most significant evaluation indexes of automotive HVAC(heating, ventilation and air conditioning), but also a compulsory test index according to vehicle national standard, for it involves driving safety. Traditional design method of defrosting duct depends too much on experience. However, irregular shape and complex structure makes the design difficult while experimental design method costs too much time and money ${ }^{[1,2]}$. So distribution of airflow velocity on the surface of windshield was researched by numerical calculation to predict defrosting performance ${ }^{[3]}$.

This paper calculated the model of defrosting duct of a light bus with CFD (computational fluid dynamics) method to research its flow field features and analyze airflow velocity and flow rate of each outlet. The distribution of air flow velocity on the surface of windshield was also concerned.

Meshed model(shown in figure 1) was imported in FLUENT to simulate by k- $\varepsilon$ algorithm. Inlet was set as MASS_FLOW_INLET and mass flow rate was $0.168 \mathrm{~kg} / \mathrm{s}$. Outlet was set as PRESSURE_OUTLET and pressure was 0.

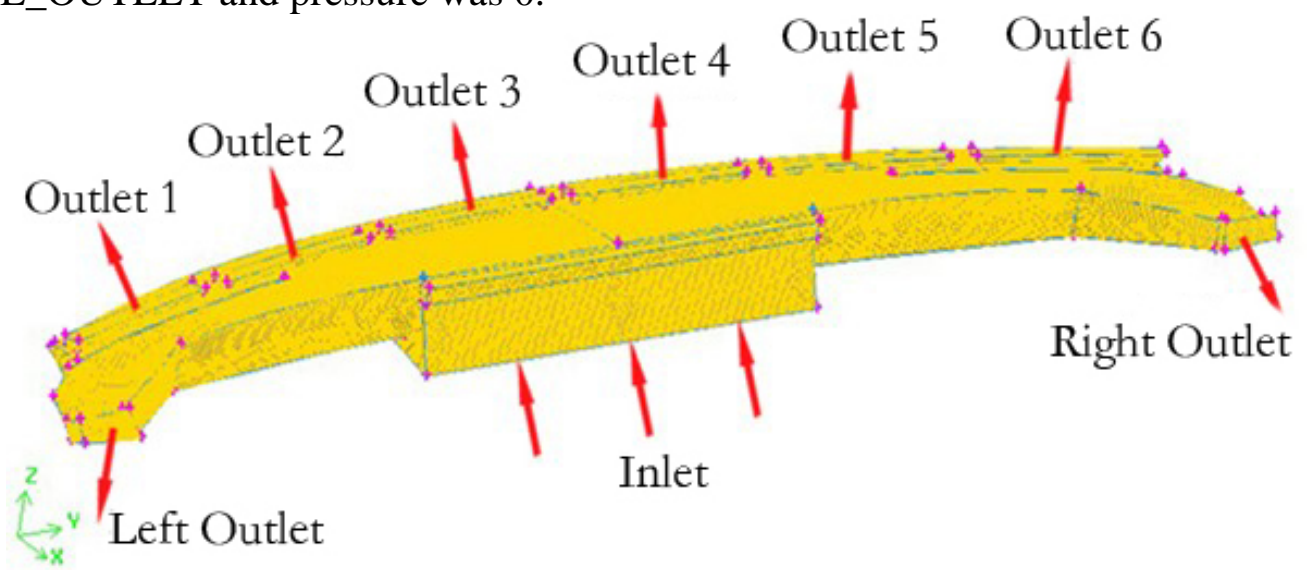

Fig.1 Meshed model of defrosting duct

\section{Distribution of outlet mass flow rate}

As shown in figure 1, airflow flowed from the inlet bottom into defrosting duct with mass flow rate of $0.168 \mathrm{~kg} / \mathrm{s}$ (equal to $470 \mathrm{~m}^{3} / \mathrm{h}$ ) and flowed out from the eight outlets. Airflow out from outlet 1 
to outlet 6 swept over windshield while airflow out from outlet 7 and outlet 8 swept over side window glass. As model calculated in FLUENT, mass flow rate of each outlet was acquired and shown in Table 1.

In the six windshield outlets, the two lateral outlets(outlet 1 and outlet 6 ) got the most mass flow rate(respectively $16.67 \%$ and $16.68 \%$, which was extremely higher than other outlets). This distribution was mainly caused by the inner structure of defrosting duct(shown in figure 2). The narrow lateral part of the duct made the flow pressure in this area higher, which could lead to higher flow rate. The total flow ratio of outlet 2 to outlet 5 was $45.70 \%$, lower than expected ratio (up to $66 \%$ ). The sum of the two side outlets flow ratio was $20.40 \%$, and this ratio did not meet the expected demand range from $12 \%$ to $14 \%$.

Tab.1 Distribution of mass flow rate

\begin{tabular}{|c|c|c|c|c|}
\hline outlet & $\begin{array}{l}\text { Mass flow rate } \\
\qquad(\mathrm{kg} / \mathrm{s})\end{array}$ & $\begin{array}{r}\text { Calculate } \\
\text { rc }\end{array}$ & ass flow & $\begin{array}{c}\text { Expected mass flow } \\
\text { ratio }\end{array}$ \\
\hline Outlet 1 & 0.028004633 & & & - \\
\hline Outlet 2 & 0.018068103 & $10.75 \%$ & \multirow{4}{*}{$45.70 \%$} & \multirow{4}{*}{$66 \%$} \\
\hline Outlet 3 & 0.020280484 & $12.07 \%$ & & \\
\hline Outlet 4 & 0.020336067 & $12.10 \%$ & & \\
\hline Outlet 5 & 0.018098608 & $10.77 \%$ & & \\
\hline Outlet 6 & 0.028025195 & \multicolumn{2}{|c|}{$16.68 \%$} & - \\
\hline Left outlet & 0.017600249 & $10.48 \%$ & \multirow{2}{*}{$20.94 \%$} & \multirow{2}{*}{$12-14 \%$} \\
\hline Right outlet & 0.017585600 & $10.47 \%$ & & \\
\hline sum & 0.167999980 & \multicolumn{2}{|c|}{$100 \%$} & - \\
\hline
\end{tabular}

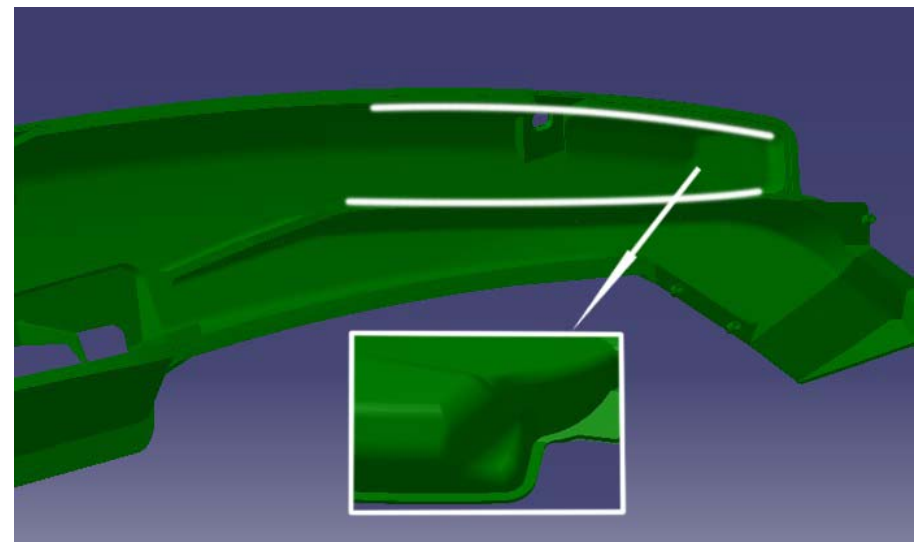

Fig.2 Detailed structure of defrosting duct

\section{Jet velocity of outlets}

Cross sections of 8 outlets were extracted for acquiring the jet velocity distribution which was shown in figure 3 to figure 4 . In figure 3 the visible area showed the outlet distribution of jet velocity higher than $0 \mathrm{~m} / \mathrm{s}$ while visible area in figure 4 showed that of jet velocity higher than 6 $\mathrm{m} / \mathrm{s}$. maximum jet velocity got as high as $11.7 \mathrm{~m} / \mathrm{s}$. detailed distribution of jet velocity of outlet 1 was shown in figure 5 and figure 6 . Only area with jet velocity higher than $9 \mathrm{~m} / \mathrm{s}$ was visible in figure 6 . It was clear that the jet velocity of area close to boundary layers was close to $0 \mathrm{~m} / \mathrm{s}$ and 
that the jet velocity of central area was high, which was caused by the rule that wall velocity was set automatically at $0 \mathrm{~m} / \mathrm{s}$.
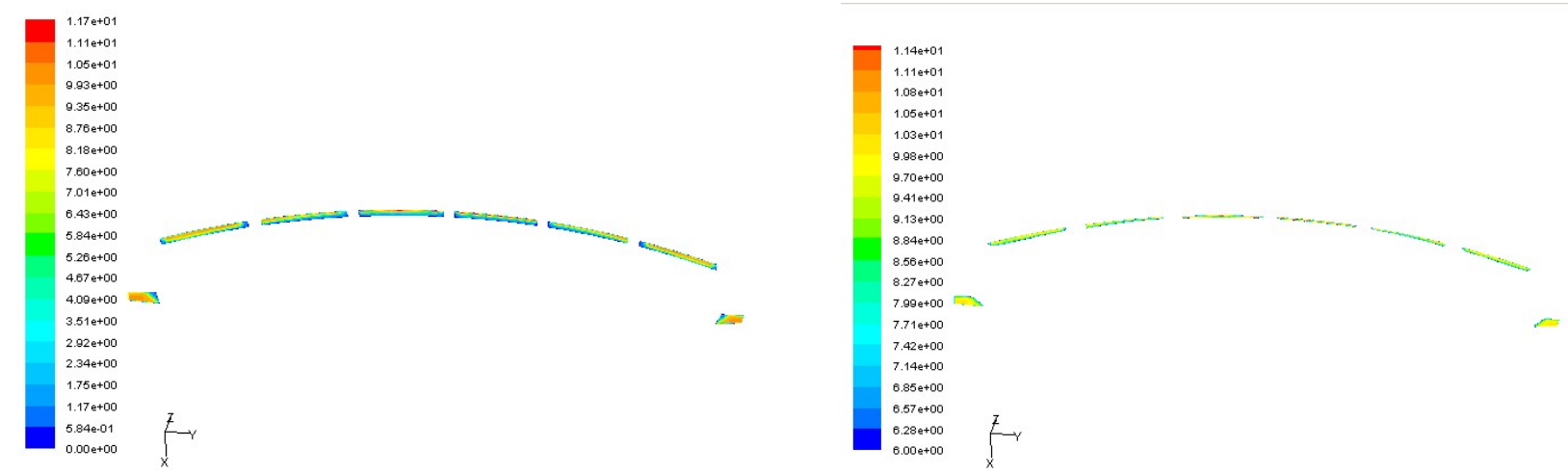

Fig.3 Jet velocity distribution of outlets $(\mathrm{v} \geqq 0 \mathrm{~m} / \mathrm{s})$ Fig.4 Jet velocity distribution of outlets( $\mathrm{v} \geqq 6$ $\mathrm{m} / \mathrm{s})$
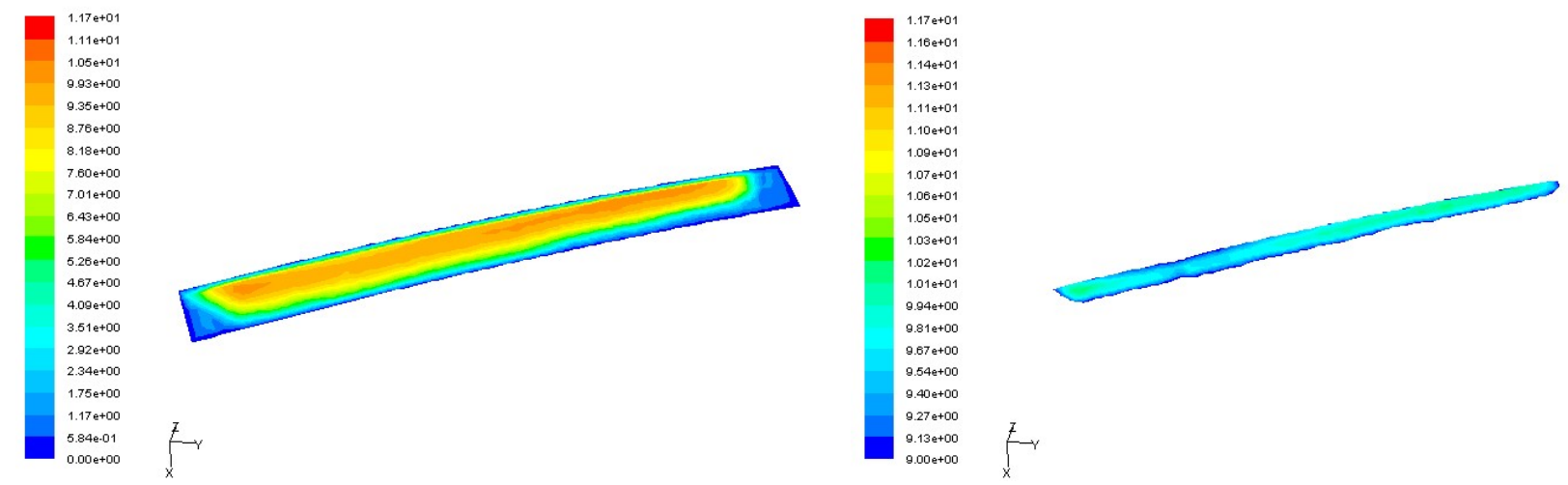

Fig.5 Jet velocity distribution of outlet $1(\mathrm{v} \geqq 0 \mathrm{~m} / \mathrm{s})$ Fig. 6 Jet velocity distribution of outlet $1(\mathrm{v} \geqq$ $9 \mathrm{~m} / \mathrm{s})$

\section{Velocity of airflow swept on the surface of windshield}

Model of airflow area inside the light bus was built for velocity distribution research of the airflow out from outlets of defrosting duct and swept on the surface of windshield. Figure 7 to figure 10 showed the velocity distribution of airflow swept on the surface of windshield. In figure 8 only area with velocity higher than $1 \mathrm{~m} / \mathrm{s}$ was visible, while in figure 9 and figure 10 respectively $1.5 \mathrm{~m} / \mathrm{s}$ and $2 \mathrm{~m} / \mathrm{s}$.

It was indicated that the airflow close to lateral side surface of wind shield got extremely high velocity(maximum velocity got as high as $7.78 \mathrm{~m} / \mathrm{s}$ ), which was coincident with the high jet velocity of lateral outlets of defrosting duct. Low airflow velocity out from outlet 2 and outlet 5 meant poor defrosting performance at this area. High velocity area(with velocity higher than $2 \mathrm{~m} / \mathrm{s}$ ) shown in figure 10 did not cover the whole area of windshield, but as shown in figure 8 , almost the whole area of windshield was covered by velocity of $1 \mathrm{~m} / \mathrm{s}$. So it could be asserted that the defrosting performance of the duct was satisfactory. However, jet velocity of lateral outlets should be lower and that of outlet 2 and outlet 5 higher so that the airflow velocity distribution close to the surface of windshield could be more even and homogenous, if any improvement suggestions for defrosting duct must be given. 

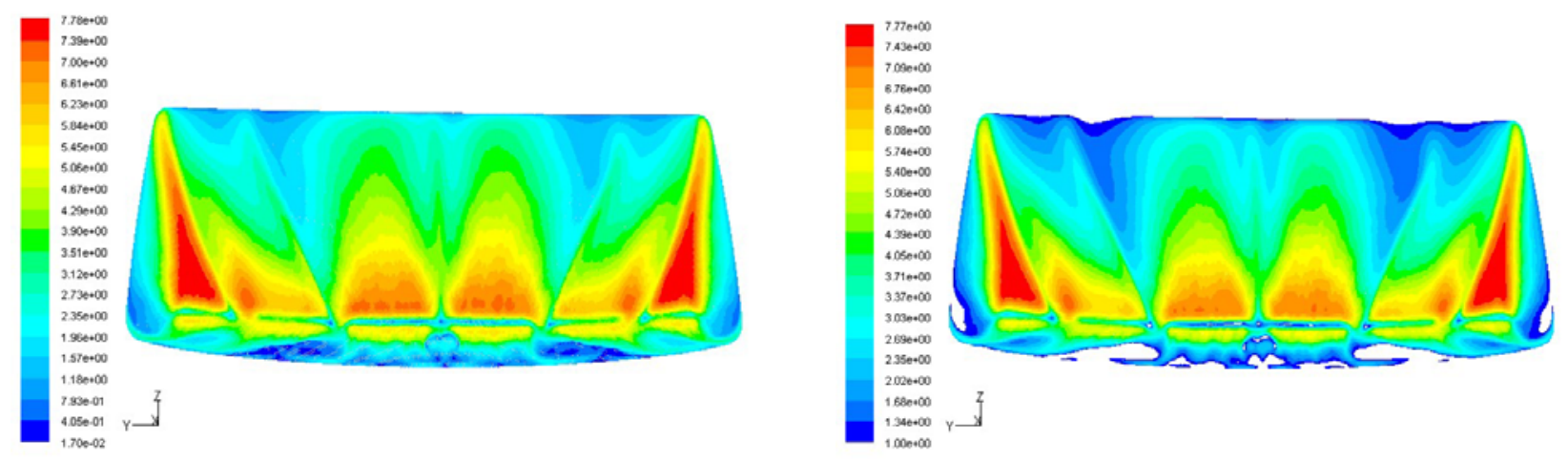

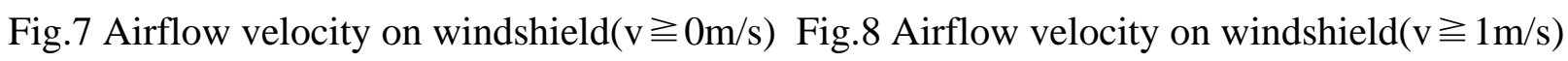
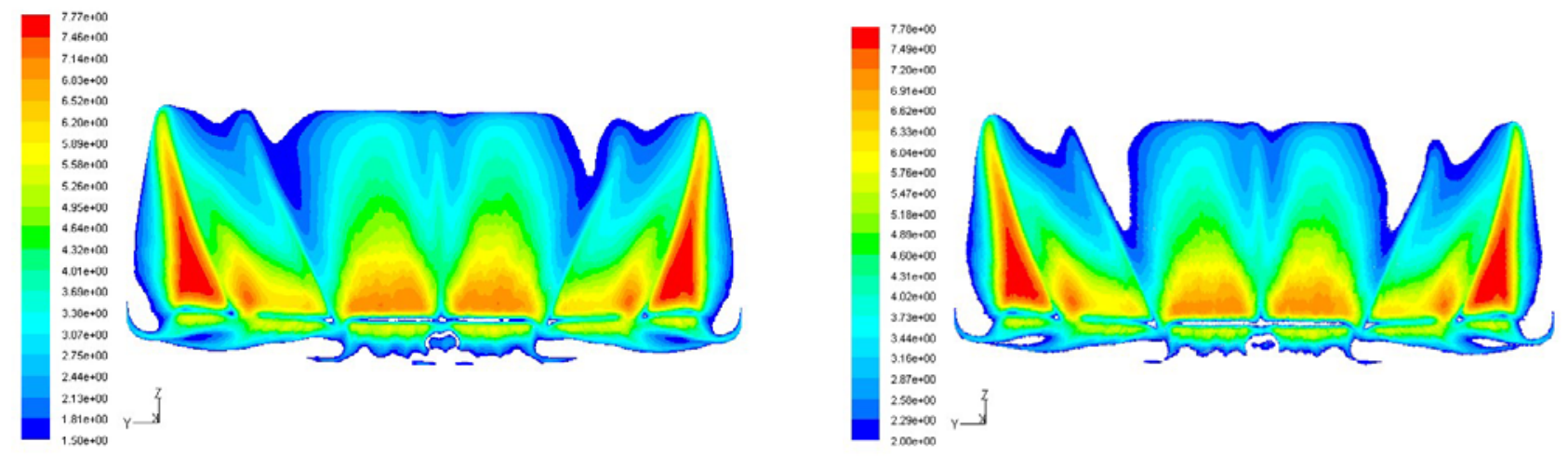

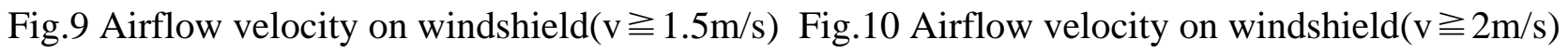

\section{Conclusion}

With the theory and method of CFD, defrosting performance of HVAC defrosting duct used in a light bus was analyzed and predicted in perspective of airflow velocity and mass flow rate. Without traditional experience and high cost experiments, application of CFD made it convenient and purposeful in defrosting duct design and improvement.

\section{References}

[1] Wu Jinyu, Chen Jiangping, CFD Analysis and Optimization of Automotive Air-conditioning defrost System[C], Acdemic annual conference papers of shanghai society of refrigeration, 2007.

[2] Zhu Juanjuan, Su Xiuping \& Chen Jiangping, A Study on Structural Optimization for Defrosting Duct of Mobile Air-Conditioner[J], Automotive Engineering, 2004(Vol.26) No.6.

[3] Chen Jiangping, Niu Yongming, Mu Jingyang \& Feng Xin, Computational Fluid Dynamic Analysis of Car Air-conditioning Duct[J], Automotive Engineering, 2002(Vol.24) No.2.

[4] Wang Fujun, Computational Fluid Dynamics Analysis---Principle and Application of CFD software[M], Tsinghua University Press, Beijing, 2004.

[5] Ma Ning, The Defrosting Performance Control and Analysis of Automobile Windshield[D], Jilin Unversity, Changchun, 2007. 